\title{
ESCATOLOGÍA Y ESPÍRITU SANTO: EL DERRAMAMIENTO DE LA LLUVIA TARDÍA Y LA MISIÓN DE LA IGLESIA
}

Ojanama Gaspar, Omar Universidad Peruana Unión omar.ojanama@upeu.edu.pe

Fecha de recepción: Abril 2014

Fecha de aceptación y versión final: Junio 2014

Para los adventistas el derramamiento del Espiritu en Pentecostés fue el cumplimiento a la promesa de la lluvia temprana. La lluvia temprana es importante para recibir la lluvia tardía; por ende, su entendimiento es pertinente. El presente artículo esboza un breve panorama histórico sobre la lluvia temprana, para luego trasladarse a explicar lo que significa para nosotros el derramamiento de la lluvia tardía. Además, es necesario preguntarnos icuáles son las condiciones para recibir esta promesa? Para responder esta pregunta, el autor, a la luz de las Escrituras y de Elena de White, divide su artículo en tres secciones, invitando a la Iglesia a permanecer fiel para poder recibir esta grandiosa promesa.

Palabras clave: Lluvia tardía, Pentecostés, Elena de White 


\section{ESCHATOLOGY AND HOLY SPIRIT: THE OUTPOURING OF THE LATTER RAIN AND THE MISSION OF THE CHURCH}

Summary:

For Adventists the outpouring of the Spirit at Pentecost was the fulfillment of the promise of the early rain. The early rain is important in order to receive the latter rain; therefore their understanding is pertinent. This article outlines a brief historical overview of the early rain, then move to explain what we understand by the outpouring of the latter rain. Furthermore, it is necessary to ask what conditions are to receive this promise? To answer this question, the author, in the light of Scripture and Ellen White, divide his article into three sections, inviting the Church to remain faithful to receive this great promise.

Keywords: Latter Rain, Pentecost, Ellen White. 


\section{Introducción}

¿Qué es lo que traerá la lluvia tardía al pueblo de Dios? ¿Cuáles son las condiciones para recibir esa promesa? Estas son preguntas que exigen una respuesta adecuada a la luz de la Palabra de Dios y el testimonio inspirado de Elena G. de White. Ella escribió en 1897, "la lluvia tardía que madura la cosecha de la tierra representa la gracia espiritual que prepara a la iglesia para la venida del Hijo del hombre. Pero a menos que haya caído la

44 lluvia temprana, no habrá vida; la hoja verde no aparecerá". ${ }^{1}$

Para los adventistas el derramamiento del Espíritu en Pentecostés fue el cumplimiento a la promesa de la lluvia temprana. La lluvia temprana es importante para recibir la lluvia tardía; por ello, es importante comprender la manera y las condiciones en que los apóstoles la experimentaron, por lo que se hace necesario examinar tres elementos

1 Elena G. de White, La educación (Bogotá: Asociación Publicadora Interamericana, 2009), 188. importantes: 1) la situación histórica del derramamiento del Espíritu en Pentecostés, 2) tener una idea bíblica del significado de dicho evento y 3) tener un patrón neo-testamentario que explique dicho derramamiento en nuestros días.

\section{El derramamiento de la lluvia temprana: su situa- ción histórica}

Para comprender la actuación del Espíritu en la iglesia apostólica, el libro de los Hechos es el documento mas ilustrativo. ${ }^{2}$ En el primer capítulo, se describe la preparación para el cumplimiento de la promesa (cf. Hch 1:4). En Hechos 1:8 aparece la versión lucana de la gran comisión de Mateo 28:19 y Marcos 16:15, 16, en las cuales Cristo encarga continuar la misión evangelizadora en la tierra, tal obra únicamente seria lograda mediante el poder del Espíritu Santo.

2 Everett F. Harrison, Introducción al Nuevo Testamento (Grand Rapids, MI: Libros Desafío, 1980), 234. 
“...pero recibiréis poder cuando el Espíritu Santo venga sobre vosotros; y me seréis testigos en Jerusalén, en toda Judea y Samaria y hasta los confines de la tierra" (LBLA). ${ }^{3}$

Asimismo, es importante considerar la actitud de la naciente iglesia al aguardar la promesa del Espíritu. Hechos 2:1 menciona que en "el día de Pentecostés estaban todos unánimes juntos"; su actitud era de unidad y compañerismo fraterno, entendiéndose que se encontraban en ferviente oración y una profunda preocupación por salvar almas (cf. HA 30). ${ }^{4}$

La actitud de aguardar el derramamiento del Espíritu se manifestó en el ambiente de unidad de fe y compañerismo en

3 Nótese que en Hechos 1:8 aparecen expresiones interesantes que se hallan en todo el libro y marcan el proceso del ministerio evangelístico de la iglesia: dunamis, "poder"; hagios pneumatos, "Espíritu Santo"; martus, "testigo", "mártir".

4 Pentecostés era también conocido como "la fiesta de las semanas" (Ex 34:22) y "el día de las primicias" (Nm 28:26), en cuya ocasión se presentaban los primeros frutos o productos de la cosecha del trigo (Ex 34:22). la comunidad de cristianos en Jerusalén, pero considérese que esa no era la causa por la cual se concedía ese don. La razón o motivo para el descenso de la lluvia temprana lo explica Pedro en el sermón evangélico de Hechos 2:14-36.

\section{El derramamiento de la lluvia temprana: su expli- cación}

La explicación del derramamiento del Espíritu en lenguas de fuego se encuentra en el poderoso discurso de Pedro en el día de Pentecostés. Dos puntos fundamentales marcan el argumento del apóstol: 1) Dios había cumplido su promesa de derramar su Espíritu sobre su pueblo tal cual anunciaba el Antiguo Testamento (AT) y 2) había llegado el tiempo de la confirmación del plan de Dios en la historia, los "últimos días", que se iniciaron con la venida de Cristo, y cuya señal era la presencia escatológica de su Espíritu Santo. ${ }^{5}$

5 F. F. Bruce, Hechos de los Apóstoles (Grand Rapids, MI: Libros Desafío, 2007), 78. 
Hechos 2: 17-21 explica detalladamente la naturaleza del evento: el derramamiento escatológico del Espíritu y 2:22-33 muestra que la razón para ello fue la entronización de Cristo en el santuario celestial a la diestra del Padre. Leamos Hechos 2: 32, 33:

"A este Jesús resucito Dios, de lo cual todos nosotros somos testigos. Así que, exaltado a la diestra de Dios y habiendo recibido la promesa del Espíritu Santo, ha derramado esto que vosotros veis y oís".

Lo interesante del caso es que, a fin de confirmar su declaración, Pedro utiliza un texto del AT, el Salmo 110:1, que precisamente describe la designación del Rey mesiánico como Sumo Sacerdote del orden de Melquisedec:

"Dijo el Señor a mi Señor:

Siéntate a mi diestra,

Hasta que ponga a tus enemigos por estrado de tus pies". 6

6 En Salmo 110:4, es YHWH quien menciona al Rey mesiánico en calidad de sacerdote eterno y con una autoridad superior según un orden diferente, el de Melquisedec. Lo mismo se dirá de Cristo en
Al cumplirse todos los eventos de Pentecostés en la persona de Jesucristo, en ocasión de su ascensión al santuario, se entiende que el derramamiento del Espíritu en la lluvia temprana vino como resultado de la inauguración del ministerio sumo sacerdotal de Cristo en el templo celestial.

"La ascensión de Cristo al cielo fue la señal de que sus seguidores iban a recibir la bendición prometida. Habían de esperarla antes de empezar a hacer su obra. Cuando Cristo entró por los portales celestiales, fue entronizado en medio de la adoración de los ángeles. Tan pronto como esta ceremonia hubo terminado, el Espíritu Santo descendió sobre los discípulos en abundantes raudales, y Cristo fue de veras glorificado con la misma gloria que había tenido con el Padre desde toda la eternidad.

El derramamiento pentecostal era la comunicación del cielo de que el Redentor había iniciado su ministerio celestial" (HA, 32).

Hebreos 5:6, 6:20 y 7:11-25, a fin de confirmar su sumo sacerdocio celestial. 
Según Hechos 2:36, en el cielo, Dios había hecho a Cristo Señor (Kurios) y Cristo (Cristo). El verbo aoristo indicativo "hecho" (gr. epoíesen) significa "hacer", "preparar", "establecer", "ordenar". En el pensamiento griego, poíeo indicaba la acción creadora de la deidad. LXX usa poieo para señalar la acción divina en la historia salvífica, la obra de redención que solo Dios puede realizar, como la liberación del éxodo (Ex 13:8). Hebreos 3:2 usa poíeo para "designar" a Cristo como sumo sacerdote, pero el Nuevo Testamento (NT) usa ese término específicamente para la actividad judicial y redentora de Dios (cf. Lc 18:7,8; 1:68; Heb 8:9; Ef 3:20; Rom 4:21; Hch 2:22). ${ }^{8}$ Por lo tanto, Dios ha designado judicial y soteriológicamente a Su Hijo como Señor

7 Joaquim Azevedo Neto e Isael Santos Souza Costa, Léxico analítico do grego do Novo Testamento (Cachoeira: CePLiB, 2010), 316.

$8 \mathrm{H}$, Braun, poíeo, en Compendio del Diccionario teológico del Nuevo Testamento, eds. Gerhard Kittel, Gerhard Friedrich y Geoffrey W. Bromiley (Grand Rapids, MI: Libros Desafío, 2002), 873-74. En adelante, Compendio. y Sumo Sacerdote ungido en favor de su pueblo. De hecho, la fiesta de Pentecostés fue la inauguración de la obra del Espíritu Santo como Administrador de la naciente iglesia. ${ }^{9}$

La actitud de los discípulos en elevar sus suplicas a Cristo por el derramamiento del Espíritu fue considerada por el cielo, y en el santuario "Cristo añadió su intercesión" a dichas plegarias (cf. HA, 31). Por ello, si el inicio de la obra de Cristo como sumo sacerdote celestial ocasionó el derramamiento de la lluvia temprana del Espíritu, lo mismo debe ocurrir al final de su ministerio. Ahora, a la luz de este argumento, procederemos a estudiar el derramamiento del Espíritu como lluvia tardía en los tiempos finales.

9 LeRoy Edwin Froom, La venida del Consolador, edición revisada (Buenos Aires: Asociación Casa Editora Sudamericana, 2010), 82. 
El derramamiento de la lluvia tardía en el tiempo del fin: los tiempos de refrigerio

El NT enseña que el recibimiento del Espíritu Santo como lluvia temprana se conecta con la aceptación de Cristo como salvador. Juan 7:38: "Y en el último día, el gran día de la fiesta, Jesús puesto en pie, exclamó en alta voz, diciendo: Si alguno tiene sed, que venga a mí y beba. El que cree en mí, como ha dicho la Escritura: "De lo más de agua viva”. El que cree en Jesucristo como el Mesías recibe el don del Espíritu Santo. Esto se alinea con la declaración en Efesios 1:13: "En él también vosotros, habiendo oído la palabra de verdad, el evangelio de vuestra salvación, y habiendo creído, fuisteis sellados también en él con el Espíritu Santo de la promesa". ${ }^{10}$

10 Véase Hechos 19:1-6, donde se cuenta que los discípulos de Juan reciban el Espíritu luego de aceptar el evangelio de Cristo y ser bautizados en Su nombre.

Desde Pentecostés hasta nuestros días, todo creyente cristiano recibe el don del Espíritu Santo en lluvia temprana por motivo de creer en el evangelio del ministerio celestial de Cristo. La iglesia adventista del séptimo día espera ahora el derramamiento del Espíritu como lluvia tardía y la respectiva maduración de la cosecha del evangelio en el carácter de las personas. Según Elena de White, esta obra "será semejante a la que se realizó en el día de Pentecostés. Como la lluvia 'temprana' fue dada en tiempo de la efusión del Espíritu Santo al principio del ministerio evangélico, para hacer crecer la preciosa semilla, así la 'lluvia tardía será dada al final de dicho ministerio para hacer madurar la cosecha" (EUD, 190).

Hechos 3:19 menciona el derramamiento del Espíritu en la figura de "los tiempos de refrigerio" de la presencia del Señor. Elena de White escribió que la obra del Espíritu en la lluvia tardía seria semejante a la obra "que se realizó en el día de Pentecostés". Esto tiene conexión 
con la obra de Cristo en el santuario como sumo sacerdote.

"...de la presencia del Señor". "Presencia" en griego es prósopon, e indica "rostro", "cara" y frecuentemente se usa para señalar el rostro de Dios o su presencia en el santuario celestial (cf. Sal 42: 2-4; Zac 8: 2122). ${ }^{11}$ Es en el santuario donde también se encontraba el pan de la proposición o de la presencia (1 Sam 21:6), el pan del prosopon. ${ }^{12}$

Prosopou tou kuriou, "la presencia del Señor" de Hechos 3:19 tiene una correspondencia teológica con Hebreos 9: 24: "Porque no entró Cristo en un lugar santo hecho de manos... sino en el cielo mismo, para presentarse ahora en la presencia de Dios (prosopou tou theou) por nosotros". Así como los adoradores del AT "ven el rostro de Dios" al ingresar al santuario, Hebreos 9:24 afirma que Cristo comparece ante el rostro/pre-

11 En LXX, prosopon se usa algunas veces para indicar visitar a Dios en el santuario. E. Lohse, prósopon, -Compendio, 928.

12 Ibid. sencia de Dios en el tabernáculo del cielo. ${ }^{13}$ Es desde el mismo lugar santísimo del santuario que Dios enviará "el refrigerio" del Espíritu en lluvia tardía. Así como Cristo derramó su precioso don en Pentecostés al iniciar su obra intercesora, ¿qué actividad final en su santuario permitirá derramar la lluvia tardía?

Pues Jesús se encuentra ahora en el lugar santísimo ministrando el borramiento de los pecados de Su pueblo desde 1844, en el juicio investigador (cf. CES 97; CS 416). El borramiento de los pecados del pueblo de Dios y la actividad divina de Juicio están íntimamente relacionados:

"Yo, yo soy el que borro tus transgresiones por amor

A mí mismo, y no recordare tus pecados.

Hazme recordar, entremos en juicio juntamente

Habla tú para justificarte" (Is 43:25-26, RV60).

El inicio del ministerio de Cristo en el cielo abrió el camino para el perdón de los pecados (Hch 13:32-33; 38-39) y

$13 \quad$ Ibid., 929. 
derramó el Espíritu Santo para equipar a su iglesia con poder especial para evangelizar al mundo conocido (Hch 2:33). De forma análoga, se sugiere ahora que el ministerio final de Cristo de borrar los pecados de su iglesia y capacitarlos poderosamente para proclamar el fuerte pregón del tercer ángel. ${ }^{14}$

"Oí que los revestidos de la armadura proclamaban poderosamente la verdad, con fructuosos resultados [...] Pregunté por la causa de tan profundo cambio y un ángel me respondió: 'Es la lluvia tardía; el refrigerio de la presencia del Señor; el potente pregón del tercer ángel” (PE 271; EUD, 191).

A la luz de este testimonio inspirado, se comprende que la lluvia tardía tiene conexión intrínseca con la predicación del fuerte pregón-y no solamente es un poder especial para soportar

14 Ron E. M. Clouzet ha elaborado una interesante descripción de la preparación devocional para recibir la lluvia tardía en la vida del remanente en La mayor necesidad del adventismo: El derramamiento del Espíritu Santo (Buenos Aires: Asociación Casa Editora Sudamericana, 2012), 177-185. el tiempo de angustia final. Este mensaje del fuerte pregón tiene relación especial también con la verdad del santuario y la justificación por la fe. La lluvia tardía, que proviene del santuario, es la predicación de la salvación por la fe en el lugar santísimo, precisamente de donde Jesús envía su poderoso derramamiento del Espíritu.

"El tercer ángel... señalaba al santuario celestial. La atención de cuantos aceptan este mensaje se dirige hacia el lugar santísimo, donde Jesús está de pie delante del arca, realizando su intercesión final por todos aquellos para quienes hay todavía misericordia" (PE 254).

"Varios me han escrito preguntándome si el mensaje de la justificación por la fe es el mensaje del tercer ángel, y he contestado: "Es el mensaje del tercer ángel en verdad". -The Review and Herald, 1 de abril de 1890".

El mensaje del tercer ángel revela la justificación gratuita del pecador por la fe en la obra expiatoria de Cristo y es por esa obra que somos aceptados ante el Padre (cf. Rom 3:24, 28; 
Fil 3:9); es por la fe en esa obra expiatoria que los pecados del pueblo remanente son borrados (eliminados) en el juicio y es por la fe en esa obra redentora que se recibe el Espíritu Santo (Col 3:2) y el don esperado de la lluvia tardía (Hch 3: 16, 19). El aceptar-y obedecer-con fe las buenas nuevas de la salvación por Cristo en el santuario permite tener acceso a todas las bendiciones disponibles en el almacén celestial para su pueblo.

\section{A modo de conclusión}

La iglesia primitiva recibió el don de la lluvia temprana por causa del inicio del ministerio sumo sacerdotal de Cristo en el santuario celestial. La actitud de los apóstoles fue la de aguardar tal promesa con fe, oración y testificación. Según el testimonio bíblico y los escritos de la Sra. White, se considera que algo parecido debe suceder en el tiempo final: la lluvia tardía debe caer sobre la iglesia remanente cuando esta reconoce y acepta la verdad del ministerio final de
Cristo en el lugar santísimo en, "la intercesión final" para el pueblo de Dios. La Palabra de Dios nos llama a acercarnos por la fe a Cristo en su obra final que se efectúa en el cielo.

"Entonces, hermanos, puesto que tenemos confianza para entrar al Lugar Santísimo por la sangre de Jesús, por un camino nuevo y vivo que $\mathrm{El}$ inauguró para nosotros por medio del velo, es decir, su carne, y puesto que tenemos un gran sacerdote sobre la casa de Dios, acerquémonos con corazón sincero, en plena certidumbre de fe" (Heb 10:19-22).

"En plena certidumbre de fe". Cuando la iglesia se aferre incondicionalmente a las promesas de Dios y observe cuidadosamente la importancia de la obra sumo sacerdotal de Cristo al borrar los pecados de su pueblo, tendrá la actitud adecuada y la comprensión debida de su papel en la recepción de la lluvia tardía en unanimidad de corazón y celo en terminar la obra evangelizadora del evangelio. 